\title{
Occupational lead neurotoxicity: improvement in behavioural effects after reduction of exposure
}

\author{
E L BAKER,,${ }^{2}$ ROBERTA F WHITE, ${ }^{2}$ LUCILLE J POTHIER, ${ }^{1}$ CATHERINE S BERKEY, ${ }^{3}$ \\ G E DINSE, ${ }^{4}$ PATRICIA H TRAVERS, ${ }^{2} \mathrm{~J}$ P HARLEY, ${ }^{25}$ AND R G FELDMAN ${ }^{12}$
}

From the Occupational Health Program, ${ }^{1}$ Department of Environmental Science and Physiology, Harvard School of Public Health, Boston, MA, Department of Neurology, ${ }^{2}$ Boston University Medical Center, Boston, MA, Channing Laboratory, ${ }^{3}$ Department of Medicine, Harvard Medical School, Boston, MA, Department of Biostatistics, ${ }^{4}$ Harvard School of Public Health, Boston, MA, and Department of Neuropsychology, ${ }^{5}$ Braintree Hospital, Braintree, MA, USA

ABSTRACT To evaluate critical exposure levels and the reversibility of lead neurotoxicity a group of lead exposed foundry workers and an unexposed reference population were followed up for three years. During this period, tests designed to monitor neurobehavioural function and lead dose were administered. Evaluations of 160 workers during the first year showed dose dependent decrements in mood, visual/motor performance, memory, and verbal concept formation. Subsequently, an improvement in the hygienic conditions at the plant resulted in striking reductions in blood lead concentrations over the following two years. Attendant improvement in indices of tension (20\% reduction), anger (18\%), depression (26\%), fatigue $(27 \%)$, and confusion $(13 \%)$ was observed. Performance on neurobehavioural testing generally correlated best with integrated dose estimates derived from blood lead concentrations measured periodically over the study period; zinc protoporphyrin levels were less well correlated with function. This investigation confirms the importance of compliance with workplace standards designed to lower exposures to ensure that individual blood lead concentrations remain below $50 \mu \mathrm{g} / \mathrm{dl}$.

In our experience central nervous system toxicity due to excessive lead absorption occurs at lower levels of exposure than dysfunction of the peripheral nervous system.' Slowing of nerve conduction and overt neuropathy usually appear after more intense or more prolonged exposure. Although other systemic effects may occur with modest levels of exposure, nervous system disorders have a greater impact on the ability of the individual to work and to perform the activities of daily life. Furthermore, since the nervous system has a limited regenerative capacity, lead is more likely to cause persistent functional neurological impairment than damage to other organ systems.

Most previous reports, based on cross sectional studies, describe a variety of lead related neuropsychological effects: impairment of verbal ability, memory, and visual/motor performance, as well as alterations in mood (table 1). ${ }^{2-6}$ Prospective studies following up the course of lead neurotoxicity are

Received 24 September 1984 Accepted 12 November 1984 limited but reversibility of the slowing of nerve conduction after chelation therapy has been reported in a study of 14 workers.' Seppålainen and Hernberg evaluated 23 battery workers before and one and two years after entering lead exposed jobs. ${ }^{8}$ Prolongation of the motor distal latency of the median nerve and slowing of distal sensory velocity in the sural nerve were observed in individuals whose blood lead concentrations rose to levels no higher than $48 \mu \mathrm{g} / \mathrm{dl}$. In a third prospective study nerve conduction studies on lead exposed workers and a reference group were performed on two occasions, 12-18 months apart.9 Mean nerve conduction velocities and latencies did not differ significantly between the two groups on either the first or the second testing; blood lead concentrations did not change appreciably between the two examinations. Another report used behavioural testing before, and two years after, the start of exposure.$^{10}$ Deterioration in performance was noted, particularly on the block design, Santa Ana coordination, and digit span tests in the exposed workers; by contrast, improvement in test performance was seen in age matched referents. 
Table 1 Summary of results of earlier cross sectional studies of behavioural effects of occupational lead exposure

\begin{tabular}{|c|c|c|c|c|}
\hline \multirow[t]{2}{*}{ Study } & \multicolumn{4}{|c|}{ Behavioural parameter } \\
\hline & Verbal ability & Memory & Visual/motor function & Mood \\
\hline 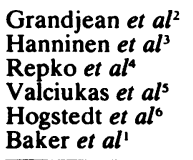 & $\frac{\downarrow}{0} \frac{1}{\downarrow}$ & $\frac{\downarrow \downarrow}{\downarrow}$ & $\downarrow$ & $\frac{\bar{z}}{\overline{-}}$ \\
\hline
\end{tabular}

0 No effect. $\downarrow \downarrow$ Impaired. $\downarrow$ Slightly impaired. - Not evaluated.

None of these prospective studies has reported follow up evaluations after reduction in lead exposure.

In the current study we evaluated the reversibility of behavioural toxicity after a reduction in lead exposure in the workplace resulting from the implementation of the standard for occupational exposure to lead promulgated by the US Occupational Safety and Health Administration (OSHA) in $1978 . "$ In the present report we summarise the results of the behavioural testing in this three year evaluation; preliminary results from the first year have been discussed elsewhere.'

\section{Methods}

\section{SUBJECTS}

During the first year of study (1980-1), we evaluated 106 lead exposed foundry workers and 65 unexposed workers. Using criteria previously described, ${ }^{1}$ we excluded certain individuals from the data analysis and from future testing, leaving 99 exposed and 61 unexposed workers as the basis of our previous analyses (table 2). More subjects were lost between years one and two than between years two and three. In the second year (1981) we retested 43 exposed workers and 34 unexposed workers. Of the 56 eligible exposed workers who were not retested, 35 had quit their jobs during the second year, eight had been fired, six were laid off, and seven refused to be retested. To our knowledge, none left employment because of work related ill-

Table 2 Summary of subject participation

\begin{tabular}{ccc}
\hline Exposed & Unexposed \\
\hline 106 & $\begin{array}{c}\text { Tested: year 1 } \\
\text { Excluded }\end{array}$ \\
Available for analysis \\
Lost to follow up \\
Retested: year 2
\end{tabular}

*See text for exclusion criteria. ness. Thus we could evaluate $86 \%(43 / 50)$ of the exposed workers remaining with the company. One unexposed and three exposed workers were tested in year two but were subsequently excluded from the analysis because they consumed alcohol less than two hours before testing. In year three (1982) 38 exposed and 19 unexposed workers were retested and six newly hired exposed workers were evaluated. Five unexposed workers tested in year three were excluded from the analysis for reasons similar to those used in year one: history of neurological disease, use of psychoactive drugs, and significant exposure to neurotoxins outside work. Two exposed workers were also excluded because of a history of solvent exposure or because incomplete data were available. After these exclusions 73 individuals were tested on two or three occasions and were available for the prospective analysis. Everyone in this group received some form of testing but not everyone completed the entire set of tests. As a result, the numbers of individuals included in tables 7-9 are slightly fewer than 73 .

All the participants were informed of the risks and benefits of the study and received direct notification of their test results. The employer had access only to data required by Occupational Safety and Health Administration (OSHA) regulations." Decisions about placing individuals on medical removal protection as specified in the OSHA lead standard were made by company personnel independent of the study. In all instances the decision to remove individuals from exposure to lead was based on raised blood lead concentrations. The workers were drawn from two plants, a brass foundry and a neighbouring assembly plant. Our initial evaluations were performed in 1980-1; follow up testing took place in the summers of 1981 and 1982 (table 2).

\section{TEST PROCEDURES}

In years two and three the questionnaire, the physical examination, the procedure for blood and urine analysis, and the nerve conduction techniques (year two only) were identical with those used in year one; they are described elsewhere.' The battery of neurobehavioural tests used in years two and three 
Table 3 Neurobehavioural test battery components by year*

\begin{tabular}{|c|c|c|c|}
\hline & \multicolumn{3}{|c|}{ Year } \\
\hline & 1 & 2 & 3 \\
\hline \multirow{7}{*}{$\begin{array}{l}\text { Verbal ability: } \\
\text { Vocabulary (WAIS)-modified } \\
\text { Similarities (WAIS) } \\
\text { Memory: } \\
\text { Digit span (WAIS-WMS) } \\
\text { Digit symbol-recall } \\
\text { Difificult paired associate learning test } \\
\text { Paired associate learning (WMS) } \\
\text { Visual reproduction (WMS): } \\
\text { Immediate recall } \\
\text { Delayed recall } \\
\text { Benton visual retention (form F) } \\
\text { Visual/motor function: } \\
\text { Block design (WAIS) } \\
\text { Continuous performance test† } \\
\text { Digit-symbol substitution (WAIS) } \\
\text { Santa Ana dexterity test }\end{array}$} & $\underset{\mathbf{X}}{\mathbf{X}}$ & $\underset{\mathbf{X}}{\mathbf{X}}$ & $\underset{\mathbf{X}}{\mathbf{X}}$ \\
\hline & & & \\
\hline & $\underset{\mathbf{X}}{\mathbf{X}}$ & $\begin{array}{l}\mathbf{X} \\
\mathbf{X}\end{array}$ & $\underset{\mathbf{X}}{\mathbf{X}}$ \\
\hline & $X$ & & $\mathbf{X}$ \\
\hline & $X$ & & $\begin{array}{l}\mathbf{X} \\
\mathbf{X} \\
\mathbf{X}\end{array}$ \\
\hline & & & \\
\hline & $\begin{array}{l}\underset{\mathbf{X}}{\mathbf{X}} \\
\mathbf{X} \\
\mathbf{X}\end{array}$ & $\begin{array}{l}\underset{\mathbf{X}}{\mathbf{X}} \\
\mathbf{X} \\
\mathbf{X}\end{array}$ & $\begin{array}{l}\mathbf{X} \\
\mathbf{X} \\
\mathbf{X} \\
\mathbf{X}\end{array}$ \\
\hline $\begin{array}{l}\text { Mood: } \\
\text { Profile of mood states (POMS) }\end{array}$ & $\mathbf{X}$ & $\mathbf{X}$ & $\mathbf{X}$ \\
\hline
\end{tabular}

* Other tests were performend only in year 1 , as noted in table 1 of Baker et al. ${ }^{\prime}$

† Variability in test administration procedures existed between the three years precluding use of data in longitudinal analyses.

WAIS = Wechsler adult intelligence scale.

WMS = Wechsler memory scale.

was restricted to avoid redundancy in the test components and to reduce the time of administration (table 3). Different forms of the verbal paired associated learning test were used over the three years to minimise learning effects on specific test items. Our rationale for test selection and statistical procedures for controlling for the impact of confounding variables has been previously described; and a detailed discussion of the rationale underlying the use of neurobehavioural testing may also be found elsewhere..$^{12}{ }^{13}$ Identical forms, procedures, and conditions of testing were used over the three years as specified elsewhere. ${ }^{14-18}$ The same neuropsychologist and neuropsychological technicians tested all the subjects evaluated in years two and three. Blood lead and erythrocyte protoporphyrin concentrations (table 4) were determined from ven- ous blood samples using anodic stripping voltammetry $^{19}$ and spectrofluorometry ${ }^{20}$ respectively by a commercial laboratory (Environmental Science Associates, Bedford, MA) within 24 hours of collection. All samples were analysed in duplicate and reanalysed if the initial duplicates did not agree within $5 \%$.

\section{STATISTICAL ANALYSIS}

To assess test reproducibility between the first, second, and third years of our study, Pearson correlation coefficients ( $r$-values) were calculated for the unexposed in order to compare the test performance from year one with years two and three.

To evaluate the relation of prior exposure to test performance, we developed exposure indices using blood lead concentrations that had been measured regularly over the 15 months before the neurobehavioural testing performed in June or August 1981. For each individual, actual blood lead concentrations were entered with the date of sample collection. Using linear extrapolation, blood lead concentrations for each month were estimated for those months during which actual blood lead determinations were not performed. As a result, a series of blood lead concentration values existed for each individual beginning with the date of initial testing and extending through the entire study period. The 44 employees of the foundry who had between two and six blood lead concentrations determined over this period are included in this analysis. These values were used to generate five exposure indices based on blood lead concentration: blood lead concentration on the day of neurobehavioural testing (current), maximum blood lead concentration over the 15 month period (max), time weighted average blood lead concentration over the 15 months (average), another average, using weights derived from a quadratic function, which weighted recent exposures more heavily than past exposures (quadratic average), and a time weighted average using only blood lead concentrations exceeding a threshold of $\mathbf{4 0}$

Table 4 Blood lead and zinc protoporphyrin (ZPP) concentrations by year and job category

\begin{tabular}{|c|c|c|c|c|c|}
\hline \multirow[t]{2}{*}{ Job category } & \multicolumn{3}{|c|}{ Mean blood lead concentration ( $\mu g / d l)$} & \multicolumn{2}{|c|}{ Mean $Z P P$ concentration ( $\mu g / d l)$} \\
\hline & 1980 & 1981 & 1982 & 1981 & 1982 \\
\hline $\begin{array}{l}\text { Melter } \\
(n=5-7) \\
\text { Grinder } \\
(n=8-11) \\
\text { Maintenance } \\
(n=3-8) \\
\text { Hunter operator } \\
(n=3-6) \\
\text { Coremaker } \\
(n=7-18) \\
\text { Unexposed workers } \\
(n=14-61)\end{array}$ & $\begin{array}{l}66 \cdot 4 \\
(43-80) \\
54 \cdot 8 \\
(33-72) \\
46 \cdot 1 \\
(38-58) \\
36 \cdot 8 \\
(23-60) \\
31 \cdot 4 \\
(15-50) \\
25 \cdot 1 \\
(10-42)\end{array}$ & $\begin{array}{l}49 \cdot 3 \\
(41-59) \\
38 \cdot 3 \\
(19-56) \\
35 \cdot 1 \\
(19-51) \\
24 \cdot 7 \\
(15-59) \\
24 \cdot 6 \\
(16-37) \\
22 \cdot 9 \\
(7-37) .\end{array}$ & $\begin{array}{l}36 \cdot 8 \\
(23-46) \\
32 \cdot 7 \\
(19-50) \\
31 \cdot 7 \\
(31-33) \\
24 \cdot 3 \\
(13-36) \\
23 \cdot 5 \\
(12-42) \\
21 \cdot 5 \\
(8-31)\end{array}$ & $\begin{array}{l}118 \cdot 9 \\
(28-278) \\
42 \cdot 3 \\
(15-147) \\
39 \cdot 6 \\
(9-100) \\
36 \cdot 0 \\
(11-106) \\
48 \cdot 4 \\
(17-71) \\
21 \cdot 8 \\
(9-55)\end{array}$ & $\begin{array}{l}78 \cdot 0 \\
(22-138) \\
49 \cdot 0 \\
(23-203) \\
31 \cdot 0 \\
(23-42) \\
32 \cdot 0 \\
(23-41) \\
44 \cdot 7 \\
(16-123) \\
23 \cdot 6 \\
(15-45)\end{array}$ \\
\hline
\end{tabular}



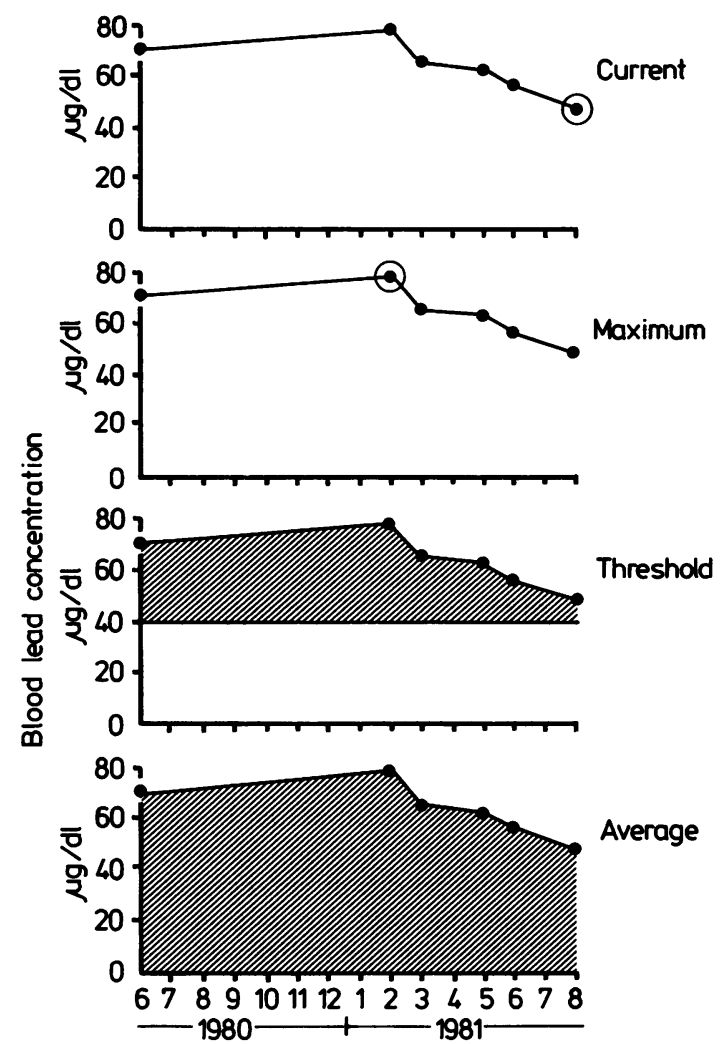

Blood lead concentrations and exposure indices for an exposed worker. Linear extrapolation was used between measured values.

$\mu \mathrm{g} / \mathrm{dl}$ (threshold average). Figure 1 depicts the blood lead concentration profile for a foundry employee tested from June 1980 to August 1981; examples of four of the five lead exposure indices for that individual are represented by points or shaded areas under the curve. (See appendix for statistical description.) If individuals were employed for less than the entire 15 months their blood lead concentration before hire was assumed, for these calculations, to be equal to the mean of the unexposed - employees of the assembly plant.

These different exposure measures were developed to facilitate the exploration of various biological hypotheses concerning lead neurotoxicity. Some neurotoxic effects of lead may be mediated through rapidly reversible neurochemical and membrane changes which fluctuate directly in proportion to the current lead concentrations in blood and central nervous system tissue. Other aspects of nervous system dysfunction may result from cumulative damage to neural structures. If damage is reversible recent exposure levels should be more important determinants of the intensity of dysfunction than past levels. Alternatively, the degree of damage may be proportional to the peak level of lead absorption rather than to average exposure. Finally, some processes may not be affected until a threshold concentration within the nervous system is exceeded. These various models of disease pathogenesis may be explored by using different exposure indices as in this study and in previous investigations. ${ }^{36}$

The exposure indices, and the zinc protoporphyrin concentration on the day of testing, were used as predictor variables in multiple linear regression models, which also included terms for several possible confounding factors: age, sex, educational level, and parental socioeconomic status as measured by the method of Hollingshead. ${ }^{21}$ Separate analyses were performed using the five predictor variables (one exposure index and the four confounding factors) for each neurobehavioural test. One tailed significance levels ( $p$ values) were then calculated for each exposure coefficient, to indicate whether or not lead exposure had a deleterious effect on performance. A one tailed approach is justified since previous research does not indicate that lead exposure improves nervous system function. Overall correlations ( $\mathrm{r}^{2}$-values) for the full model were also calculated as indicators of the percentage variability in the test scores explained by the multiple regression.

To relate changes in exposure level to changes in test performance, individuals were grouped according to their initial blood lead concentration obtainec when they were first tested (either in year one of year two). Their average annual change in test performance for each of the neurobehavioural tests was calculated using the results of testing on two or three occasions. Mean annual test change and mean annual blood lead concentration change were calculated for three groups: those whose first blood lead concentrations were $50 \mu \mathrm{g} / \mathrm{dl}$ or greater, 30 to 49 $\mu \mathrm{g} / \mathrm{dl}$, or less than $30 \mu \mathrm{g} / \mathrm{dl}$.

\section{Results}

\section{BLOOD LEAD CONCENTRATIONS}

During the study period (1980-2), the foundry was subject to the implementation of the OSHA lead standard that required a progressive lowering of blood lead concentrations at the plant. To comply with the regulations, the company improved its ventilation system, developed a respirator programme, monitored work practices, provided work clothing, provided worker education, and performed other activities to control exposure to lead. As a result of these activities, blood lead concentrations fell during the course of the study (table 4). In 1980 the highest blood lead concentration was $80 \mu \mathrm{g} / \mathrm{dl}$ whereas in 
Table 5 Correlation of year 1 results with years 2 and 3: results for unexposed workers

\begin{tabular}{lll}
\hline Test & \multicolumn{2}{l}{ Correlation coefficient $(r)$} \\
\cline { 2 - 3 } & $\begin{array}{l}\text { Year } 1 \text { v } 2 \\
(n=33)\end{array}$ & $\begin{array}{l}\text { Year } 1 \text { v } 3 \\
(n=13)\end{array}$ \\
& & \\
Verbal ability: & 0.93 & 0.91 \\
Vocabulary & 0.44 & 0.54 \\
Similarities & & \\
Memory: & & \\
Digit span: & 0.28 & 0.41 \\
Forward & 0.39 & 0.02 \\
Backward & 0.71 & 0.53 \\
Digit symbol-recall & 0.09 \\
Verbal paired associate learning* & 0.59 & \\
Visual/motor performance: & 0.71 & 0.87 \\
Block design & 0.79 & 0.91 \\
Digit symbol substitution & & \\
Santa Ana dexterity: & 0.63 & 0.65 \\
Preferred hand & 0.52 & 0.43 \\
Non-preferred hand & 0.61 & 0.54 \\
Both hands & & \\
Mood: & & \\
Profile of mood states: & 0.26 & 0.55 \\
Tension & 0.38 & 0.38 \\
Depresson & 0.20 & 0.75 \\
Anger & 0.23 & 0.51 \\
Vigour & 0.52 & 0.28 \\
Fatigue & 0.20 & 0.60 \\
Confusion & &
\end{tabular}

*Different versions of test given in years 1,2 , and 3 .

1981 no one had a blood lead concentration greater than $60 \mu \mathrm{g} / \mathrm{dl}$; in 1982 the highest blood lead concentration was $50 \mu \mathrm{g} / \mathrm{dl}$. These changes in lead dose provided the opportunity to evaluate their impact on health.

\section{TEST REPRODUCIBILITY}

The test scores showed a high degree of reproducibility for most of the tests administered (table 5). Particularly high degrees of reproducibility were noted for the vocabulary, digit symbol, block design, and verbal paired associate learning tests. The profile of mood states inventory (POMS) was less reproducible than the other tests, as expected in view of the inherent variability of mood states. Since different versions of the verbal paired associate learning test were administered in years one and two, the degree of reproducibility was encouraging.

\section{EXPOSURE RESPONSE RELATIONSHIPS}

Multiple regression analyses of test performance in year two of the study showed significant associations between the six exposure indices and the scores on some of the POMS subtests, the paired associate learning test, and the Santa Ana dexterity test using both hands (table 6). Borderline associations ( $p$ values between 0.05 and 0.1 ) were noted between isolated exposure indices and scores on the vocabulary test, the block design test, and all but one of the remaining POMS subtests. Scores on the similarities, digit span, digit symbol (substitution and recall), continuous performance, and Santa Ana

Table 6 Regression analyses of neurobehavioural tests result from year two on exposure indices

\begin{tabular}{|c|c|c|c|c|c|c|c|}
\hline & \multicolumn{7}{|c|}{ Significance level for exposure variable* } \\
\hline & $Z P P$ & Current & Avg & Quad Avg & $\operatorname{Max}$ & Thld Avg & $\boldsymbol{r}^{2}$ \\
\hline $\begin{array}{l}\text { Verbal ability: } \\
\text { Vocabulary } \\
\text { Similarities }\end{array}$ & $\begin{array}{l}0.64 \\
0.43\end{array}$ & $\begin{array}{l}0.25 \\
0.21\end{array}$ & $\begin{array}{l}0.06 \\
0.18\end{array}$ & $\begin{array}{l}0 \cdot 11 \\
0 \cdot 14\end{array}$ & $\begin{array}{l}0.16 \\
0.13\end{array}$ & $\begin{array}{l}0.09 \\
0 \cdot 11\end{array}$ & $\begin{array}{l}0.46 \\
0.18\end{array}$ \\
\hline $\begin{array}{l}\text { Memory: } \\
\text { Digit span: }\end{array}$ & & & & & & & \\
\hline $\begin{array}{l}\text { Forward } \\
\text { Backward } \\
\text { Digit symbol: recall } \\
\text { Difficult paired associate learning }\end{array}$ & $\begin{array}{l}0.52 \\
0.56 \\
0.25 \\
0.08\end{array}$ & $\begin{array}{l}0.29 \\
0.57 \\
0.27 \\
0.02\end{array}$ & $\begin{array}{l}0.35 \\
0.46 \\
0.62 \\
0.05\end{array}$ & $\begin{array}{l}0.27 \\
0.40 \\
0.49 \\
0.04\end{array}$ & $\begin{array}{l}0.27 \\
0.48 \\
0.53 \\
0.04\end{array}$ & $\begin{array}{l}0.39 \\
0.40 \\
0.44 \\
0.03\end{array}$ & $\begin{array}{l}0.24 \\
0.19 \\
0.49 \\
0.33\end{array}$ \\
\hline $\begin{array}{l}\text { Visual/motor function: } \\
\text { Block design } \\
\text { Continuous performance test } \\
\text { Digit symbol substitution } \\
\text { Santa Ana dexterity: }\end{array}$ & $\begin{array}{l}0.49 \\
0.18 \\
0.25\end{array}$ & $\begin{array}{l}0.09 \\
0.39 \\
0.27\end{array}$ & $\begin{array}{l}0.26 \\
0.43 \\
0.62\end{array}$ & $\begin{array}{l}0.17 \\
0.40 \\
0.49\end{array}$ & $\begin{array}{l}0.28 \\
0.44 \\
0.53\end{array}$ & $\begin{array}{l}0.07 \\
0.33 \\
0.44\end{array}$ & $\begin{array}{l}0.35 \\
0.24 \\
0.49\end{array}$ \\
\hline $\begin{array}{l}\text { Preferred hand } \\
\text { Non-preferred hand } \\
\text { Both hands } \\
\text { Profile of mood states: }\end{array}$ & $\begin{array}{l}0.70 \\
0.89 \\
0.54\end{array}$ & $\begin{array}{l}0.27 \\
0.66 \\
0.18\end{array}$ & $\begin{array}{l}0.28 \\
0.42 \\
0.03\end{array}$ & $\begin{array}{l}0.22 \\
0.53 \\
0.05\end{array}$ & $\begin{array}{l}0.23 \\
0.39 \\
0.08\end{array}$ & $\begin{array}{l}0.21 \\
0.16 \\
0.04\end{array}$ & $\begin{array}{l}0.27 \\
0.26 \\
0.24\end{array}$ \\
\hline $\begin{array}{l}\text { Tension } \\
\text { Anger } \\
\text { Depression } \\
\text { Vigour } \\
\text { Fatigue } \\
\text { Confusion } \\
\end{array}$ & $\begin{array}{l}0.19 \\
0.05 \\
0.29 \\
0.05 \\
0.21 \\
0.34\end{array}$ & $\begin{array}{l}0.68 \\
0.08 \\
0.26 \\
0.13 \\
0.29 \\
0.10\end{array}$ & $\begin{array}{l}0.38 \\
0.02 \\
0.04 \\
0.05 \\
0.10 \\
0.03\end{array}$ & $\begin{array}{l}0.43 \\
0.03 \\
0.06 \\
0.05 \\
0.10 \\
0.03\end{array}$ & $\begin{array}{l}0.51 \\
0.05 \\
0.08 \\
0.08 \\
0.27 \\
0.07\end{array}$ & $\begin{array}{l}0.33 \\
0.02 \\
0.02 \\
0.16 \\
0.13 \\
0.02\end{array}$ & $\begin{array}{l}0.18 \\
0.37 \\
0.20 \\
0.28 \\
0.19 \\
0.22\end{array}$ \\
\hline
\end{tabular}

$\mathrm{ZPP}=$ Zinc protoporphyrin.

*Each tabulated value is the significance level ( $p$ value) associated with the coefficient of an exposure index in a multiple linear regression model. The $p$ value corresponds to a one sided $t$ test of the hypothesis that exposure has an adverse effect on test performance. The model incorporates terms that adjust for age, sex, year of schooling, and parental Hollingshead index, and the tabulated $r^{2}$ values relate to that full model. We have recorded the $r^{2}$ value which was the largest of those obtained from the six regressions. Typically these $r^{2}$ values varied by 5-10\% between different models for the same outcome. 
Table 7 Effect of lead exposure reduction on mood scores

\begin{tabular}{|c|c|c|c|c|c|c|c|c|}
\hline \multirow{2}{*}{$\begin{array}{l}\text { Initial blood } \\
\text { lead } \\
\text { concentration } \\
(\mu g / d l)\end{array}$} & \multirow[t]{2}{*}{ No } & \multirow{2}{*}{$\begin{array}{l}\text { Mean annual } \\
\text { blood lead } \\
\text { concentration } \\
\text { change }\end{array}$} & \multicolumn{6}{|c|}{ Mean annual percentage change in POMS scores* } \\
\hline & & & Tension & Anger & Depression & Vigour & Fatigue & Confusion \\
\hline $\begin{array}{l}50-80 \\
30-49 \\
10-29\end{array}$ & $\begin{array}{l}10 \\
22 \\
35\end{array}$ & $\begin{array}{r}-13.1 \\
-6.4 \\
-1.1\end{array}$ & $\begin{array}{r}-20.3 \% \\
6.4 \% \\
-7.8 \%\end{array}$ & $\begin{array}{r}-18.4 \% \\
7.3 \% \\
5.9 \%\end{array}$ & $\begin{array}{r}-25.6 \% \\
6.1 \% \\
3.7 \%\end{array}$ & $\begin{array}{r}5.4 \% \\
-3.2 \% \\
5.8 \%\end{array}$ & $\begin{array}{l}-27.4 \% \\
-14.3 \% \\
-13.4 \%\end{array}$ & $\begin{array}{r}-13.5 \% \\
-2.8 \% \\
-6.1 \%\end{array}$ \\
\hline
\end{tabular}

*A negative percent change represents an improvement in mood for all scores. (The vigour scale was reversed to achieve a consistency of presentation.)

Table 8 Effect of reduced exposure to lead on tests of verbal ability and memory

\begin{tabular}{|c|c|c|c|c|c|c|c|}
\hline \multirow{3}{*}{$\begin{array}{l}\text { Initial blood } \\
\text { lead } \\
\text { concentration } \\
(\mu g / d l)\end{array}$} & \multirow[t]{3}{*}{ No } & \multirow{3}{*}{$\begin{array}{l}\text { Mean annual } \\
\text { change in } \\
\text { blood lead } \\
\text { concentration }\end{array}$} & \multicolumn{5}{|c|}{ Mean annual percentage change in test performance* } \\
\hline & & & \multirow[t]{2}{*}{ Vocabulary } & \multirow[t]{2}{*}{ Similarities } & \multicolumn{2}{|l|}{ Digit span } & \multirow{2}{*}{$\begin{array}{l}\text { Digit } \\
\text { symbol-recall }\end{array}$} \\
\hline & & & & & Forward & Backward & \\
\hline $\begin{array}{l}50-80 \\
30-49 \\
10-29\end{array}$ & $\begin{array}{l}12 \\
22 \\
35\end{array}$ & $\begin{array}{r}-12.5 \\
-6.4 \\
-1.1\end{array}$ & $\begin{array}{r}1.9 \% \\
-0.1 \% \\
-1.6 \%\end{array}$ & $\begin{array}{l}7.6 \% \\
8.7 \% \\
4.0 \%\end{array}$ & $\begin{array}{r}1.0 \% \\
0.8 \% \\
-1.2 \%\end{array}$ & $\begin{array}{r}-2.6 \% \\
3.2 \% \\
-3.5 \%\end{array}$ & $\begin{array}{r}-0.2 \% \\
2.7 \% \\
4.9 \%\end{array}$ \\
\hline \multicolumn{2}{|c|}{$\begin{array}{l}\text { Initial blood lead } \\
\text { concentration }(\mu g / d l)\end{array}$} & No & \multicolumn{2}{|c|}{$\begin{array}{l}\text { Mean annual change in } \\
\text { blood lead concentration }\end{array}$} & ussociate learning $\dagger$ & \multicolumn{2}{|c|}{ Visual reproduction $\dagger$} \\
\hline \multicolumn{2}{|l|}{$\begin{array}{l}50-80 \\
30-49 \\
19-29\end{array}$} & $\begin{array}{r}7 \\
17 \\
12\end{array}$ & $\begin{array}{r}-13 \cdot 8 \\
-5.9 \\
-3.1\end{array}$ & \multicolumn{2}{|c|}{$\begin{array}{r}-12.2 \% \\
-5.1 \% \\
0.8 \%\end{array}$} & \multicolumn{2}{|c|}{$\begin{array}{r}4.4 \% \\
-5.6 \% \\
-2.6 \%\end{array}$} \\
\hline
\end{tabular}

*A negative percent change represents a deterioration in performance.

$\dagger$ Tests given only in first and third years.

Table 9 Effect of lead exposure reduction on tests of visual/motor function

\begin{tabular}{|c|c|c|c|c|c|c|c|}
\hline \multirow{3}{*}{$\begin{array}{l}\text { Initial blood } \\
\text { lead } \\
\text { concentration } \\
(\mu g / d l)\end{array}$} & \multirow[t]{3}{*}{ No } & \multirow{3}{*}{$\begin{array}{l}\text { Mean annual } \\
\text { change in } \\
\text { blood lead } \\
\text { concentration }\end{array}$} & \multicolumn{5}{|c|}{ Mean annual percentage change in test performance* } \\
\hline & & & \multicolumn{2}{|l|}{ WAIS } & \multicolumn{3}{|c|}{ Santa Ana test } \\
\hline & & & Block design & Digit symbol & Preferred & Non-preferred & Both \\
\hline $\begin{array}{l}50-80 \\
30-49 \\
10-29\end{array}$ & $\begin{array}{l}12 \\
22 \\
35\end{array}$ & $\begin{array}{r}-12.5 \\
-6.4 \\
-1.1\end{array}$ & $\begin{array}{l}1.4 \% \\
1.5 \% \\
1.6 \%\end{array}$ & $\begin{array}{l}5.7 \% \\
1.9 \% \\
4.7 \%\end{array}$ & $\begin{array}{r}-1.9 \% \\
-1.1 \% \\
0.8 \%\end{array}$ & $\begin{array}{l}-2.5 \% \\
-0.9 \% \\
-1.7 \%\end{array}$ & $\begin{array}{l}0.5 \% \\
6.3 \% \\
5.2 \%\end{array}$ \\
\hline
\end{tabular}

* A negative percent change represents a deterioration in performance.

WAIS = Wechsler adult intelligence scale.

(preferred hand and non-preferred hand) tests showed no clear associations with exposure after controlling for the potentially confounding effects of age, sex, education, and parental socioeconomic status. The rate of alcohol consumption was included in the regression models with the other potential confounding factors but was not used in the final analyses (table 6) since it contributed little additional explanation to the variability of test scores.

No clear patterns emerged with respect to the different exposure indices based on blood lead concentration. Since these indices were highly correlated among themselves, this lack of a clear distinction between exposure measures was not surprising. In general, correlations with ZPP levels were slightly less significant than those for the other exposure indices. The three average exposure indices (aver- age, quadratic average, threshold average) seemed to correlate with the test scores slightly better than the current or maximum blood lead concentration.

\section{EFFECT OF EXPOSURE REDUCTION ON TEST PERFORMANCE}

Individuals whose blood lead concentrations were initially greater than $50 \mu \mathrm{g} / \mathrm{dl}$ showed consistent reductions in their reports of tension, anger, depression, fatigue, and confusion (table 7). These individuals experienced an average annual reduction of $13.1 \mu \mathrm{g} / \mathrm{dl}$ in their blood lead concentrations over the study period, except for the vigour subtest, and their POMS scores improved by $13 \%$ to $27 \%$. No comparable improvement was seen in subjects with initial blood lead concentrations below $50 \mu \mathrm{g} / \mathrm{dl}$. Owing to the small number of observations and their associated variability, none of the changes in test 
scores was statistically significant $(\mathrm{p}>0.05)$.

None of the other neurobehavioural tests exhibited any significant changes over the study period when comparing those with the highest initial blood lead concentrations $(\geqslant 50 \mu \mathrm{g} / \mathrm{dl})$ with others with lower concentrations (tables 8 and 9). A slight improvement of comparable degree across the three exposure groups was noted on the similarities and digit symbol recall tests, consistent with a mild learning effect.

\section{Discussion}

This paper summarises the results of a three year prospective evaluation of lead exposed foundry workers and an unexposed comparison population. In the first year of this study we found that several tests of behavioural function were correlated with blood lead concentrations and we concluded that impairment of central nervous system function in adults occurred at exposure levels lower than those associated with the development of abnormalities of the peripheral nervous system; the most prominent signs of lead neurotoxicity were disturbances in mood noted in individuals with blood lead concentrations over $40 \mu \mathrm{g} / \mathrm{dl} .^{1}$ Furthermore, individuals with blood lead concentrations above $60 \mu \mathrm{g} / \mathrm{dl}$ also performed worse on certain tests of verbal ability, memory, and visual/motor function. The present analyses confirm the initial reports of mood disturbances among individuals tested during the second year of our study, in which no one had a blood lead concentration greater than $60 \mu \mathrm{g} / \mathrm{dl}$. One memory test and one visual/motor test also showed a significant negative correlation with various indices of lead absorption (table 6).

A possible explanation for some of our results is that workers, knowing the effects of lead and knowing their blood lead concentrations, may have exaggerated their symptoms, thus creating information bias in the data. This is rather unlikely because workers were unaware of their current blood lead concentrations at the time of completing the POMS scale. Most, however, had had blood testing several months before testing in years two and three. Possibly, workers, knowing their prior blood lead concentrations, could have overreported changes of mood based on their knowledge of prior high exposures. Since blood lead concentrations were falling, however, such overreporting of symptoms would have reduced the magnitude of the effect noted in table 7. Thus if information bias of this type had occurred, the effect would have been to make it more difficult to observe the effects reported here. Another possible source of information bias would be the general overreporting of symptoms as a result of being studied by an outside group. Such an effect, however, would be expected to result in a general overreporting of symptoms across all exposure categories rather than a selective one for those with high initial blood lead concentrations. The possibility that, since high exposure is associated with certain jobs, individuals in those jobs could infer that their blood lead concentrations were high and therefore overreport certain symptoms was explored. In the analyses of the data from the first year of this study such a bias was not apparent and, within job categories, POMS scores correlated directly with blood lead concentrations.

Bias due to confounding was partially controlled for by excluding individuals with relatively uncommon characteristics that might influence test performance, such as acute alcohol consumption, prior exposure to other neurotoxins, neurological disease, or a history of the use of psychoactive drugs. In a further attempt to control confounding, we used multiple regression analysis to adjust simultaneously for the effects of age, sex, education level, parental socioeconomic status, and alcohol consumption level. Therefore, although some residual confounding could have influenced the magnitude of the associations seen, strenuous efforts were made to reduce this source of bias. In the attempts to control for the confounding effects of age and other factors on test performance simple linear terms were used to express these relations. Clearly, the relations are more complex, as indicated in published reports. Therefore, we transformed some of the predictor variables during the course of our exploratory analysis of the data in an attempt to explain more of the variance in the dependent variables than was accomplished by a simple linear term. Owing to the relative paucity of the available data, complex methods of modelling the covariate structure seemed inappropriate. None of the simple transformations tried was clearly superior to the linear approach. A larger data set is needed to explore these factors further in a working population.

In the analyses (tables 7 to 9) that compared test performance for those tested on multiple occasions these individuals served as their own controls and therefore the impact of confounding was minimised. No systematic change in alcohol consumption or other relevant confounding factors was noted over the three year period among retested individuals.

As a result of the reductions in lead exposure which occurred between 1980 and 1982, the blood lead concentrations of the study population fell and a reduction in the severity of mood disturbances was noted among the individuals tested serially over this period. Workers whose blood lead concentrations were at least $50 \mu \mathrm{g} / \mathrm{dl}$ on first testing experienced 
considerable reduction in their reports of tension, anger, depression, fatigue, and confusion as measured by the POMS inventory. Individuals with lower initial blood lead concentrations did not show such clear changes in mood (table 7). Other tests of behavioural function (tables 8 and 9) showed little corresponding change.

These observations deserve further comment. The failure of psychomotor and memory functions to improve after a reduction in exposure has two possible explanations. Portions of the present data (particularly those in table 6) and those of others (table 1) indicate the association of decrements in psychomotor and memory function with raised blood lead concentrations. In the present population, which continued to work in a lead environment, failure to show an improvement in these aspects of central nervous system function may be due to a delay in the reversibility of the changes that would be expected to occur only after total cessation of exposure to lead. Some changes may persist even after total removal from exposure. Alternatively, selection factors could have resulted in the placement of individuals with relatively poor memory and psychomotor function in jobs with high exposure to lead. This possibility can be examined only with a prospective epidemiological study in which workers are tested before entering exposure. The only prospective study reported to date ${ }^{10} \mathrm{did}$, in fact, show some deterioration in performance on tests of memory and psychomotor function in workers as their blood lead concentrations rose.

The reduction in blood lead concentration in this study was considerable and of the order of magnitude associated with chelation treatment. ${ }^{22}$ Our observations are also similar to those seen after chelation treatment for lead toxicity, where improvement in mood has been consistently reported..$^{23}$ Our findings in adults are similar qualitatively to those previously reported in children. ${ }^{25}$

Most of the earlier studies of lead induced behavioural toxicity have not included scales for evaluating mood in their test batteries (table 1). The present study has shown that effects on mood of exposure to lead occur early in the course of exposure and respond to a lowering of blood lead concentration. Other neurotoxins, such as organic solvents, also appear transiently to alter mood. ${ }^{26}$ Therefore, we have included a mood inventory in the test batteries that we use in the clinical evaluation of patients exposed to neurotoxins and in a recently developed computer based neurobehavioural test system for use in field studies. ${ }^{27}$ In view of these observations, further attention should be given to the role of occupational factors (including exposure to neurotoxic agents) in the genesis of psychiatric disorders.

One purpose of this study was to investigate test measures for evaluating workers exposed to lead and other neurotoxins. The reproducibility of the test results (table 5) noted among our populations, who were examined under field conditions, is comparable with those reported when the tests are administered under laboratory conditions. ${ }^{28}$ As expected, tests of stable function such as verbal ability were more reproducible than the mood inventory. To evaluate the importance of increasing test difficulty, we administered the standard version of the paired associate learning test from the Wechsler adult intelligence scale during the first year of the study and a more difficult version during the second year. Results of the more difficult version were more strongly correlated with exposure to lead than the results of the easier standard version. In this instance, increasing the level of difficulty of a test appears to have increased its discriminating ability in detecting subtle neurotoxic effects than the easier standard version.

We were interested to note modest reductions in the blood lead concentrations in the unexposed reference group (table 4). In view of the reported reductions in airborne lead concentrations associated with the increased use of lead free gasoline and the attendant reductions in blood lead concentrations obtained in the health and nutrition evaluationce survey (HANES), the changes we observed are con-? sistent with the national trend observed during the same period. ${ }^{29}$

Over the past years, views regarding the health implications of blood lead concentrations have changed and adverse effects on health have become recognised at progressively lower concentrations. For several years most occupational health professionals agreed with Kehoe's statement that lead intoxication did not occur in individuals with blood lead concentrations below $80 \mu \mathrm{g} / \mathrm{dl}^{30}$ In a more recent summary of the relation between blood lead concentrations and various systemic effects Hernberg carefully reviewed the available data and concluded that a non-response concentration for lead induced central nervous system impairment was about $50 \mu \mathrm{g} / \mathrm{dl}$ of lead in blood. ${ }^{31}$ The recent prospective study of Mantere et al found behavioural changes in individuals with an average blood lead concentration of $30.5( \pm 9.6) \mu \mathrm{g} / \mathrm{dl} . .^{10}$ The cross sectional study of Hogstedt et al found behavioural changes in a group with a time weighted average blood lead concentration of $47 \mu \mathrm{g} / \mathrm{dl}$ and an average maximum level of $64 \mu \mathrm{g} / \mathrm{dl} .^{6}$ The present results are comparable with these reports in that workers with blood lead concentrations of between 40 and 60 
$\mu \mathrm{g} / \mathrm{dl}$ displayed behavioural toxicity in the initial analyses and a subsequent reduction in the blood lead concentration reversed some of these changes (table 7). Therefore, the accumulated evidence supports the proposition that blood lead concentrations should remain below $40 \mu \mathrm{g} / \mathrm{dl}$ in exposed workers if behavioural toxicity of chronic lead exposure is to be prevented.

We thank Betsy White, John Feldman, and Julia Salas who provided invaluable help in data collection and study organisation and Lisa Gallatin who typed the original manuscript.

Research supported in part by Research Grant No OHO984-02 from the National Institute for Occupational Safety and Health and a Center Grant No ES00002-20 from the National Institute of Environmental Health Sciences.

Requests for reprints to: Dr Edward Baker, Harvard School of Public Health, 665 Huntington Avenue, Boston, MA 02115.

\section{Appendix}

Each of the lead exposure indices may be expressed in terms of the following general weighted average measure of exposure:

$$
E\left(w_{1}, w_{2}, \ldots, w_{m}\right)=\left(\sum_{i=1}^{m} w_{i} L_{i}\right) /\left(\sum_{i=1}^{m} w_{i}\right)
$$

where $m$ is the total number of months, observed or estimated, $L_{1} . L_{2}, \ldots, L_{m}$ are the blood concentrations and $w_{1}, w_{2}, \ldots, w_{m}$ are prespecified weights. Different sets of weights yield different measures of exposure; and in particular, our five exposure indices are given by

$$
\begin{aligned}
& \text { current: } \mathrm{E}(0,0, \ldots, 0,1) \\
& \text { maximum: } \mathrm{E}\left(\delta_{1}, \delta_{2}, \ldots, \delta_{\mathrm{m}}\right) \\
& \text { average: } \mathrm{E}(1,1, \ldots, 1) \\
& \text { quadratic average: } \mathrm{E}\left(1,4, \ldots, \mathrm{m}^{2}\right) \\
& \text { threshold average: } \mathrm{E}\left(\alpha_{1}, \alpha_{2}, \ldots \alpha_{\mathrm{m}}\right)-\mathrm{T}
\end{aligned}
$$

where $T$ is some prespecified threshold level, $\alpha_{i}$ equals 1 if $L_{i}$ exceeds $T$ and 0 otherwise, and $\delta_{i}$ equals 1 if $L_{i}$ is the largest blood lead concentration and 0 otherwise. The first three exposure indices are simply the most recent blood lead concentrations, the maximum blood lead concentration, and the average blood lead concentration, respectively. The fourth index uses a set of weights that increase quadratically to emphasise recent exposure more than early exposure. The last index is the average excess among the blood lead concentrations that exceed the threshold $\mathrm{T}$.

\section{References}

' Baker EL, Feldman RG, White RA, et al. Occupational lead neurotoxicity: a behavioural and electrophysiological evaluation. Study design and year one results. $\mathrm{Br} J$ Ind Med 1984;41:352-61.

${ }^{2}$ Grandjean P, Arnvig E, Beckmann J. Psychological dysfunctions in lead-exposed workers: relation to biological parameters of exposure. Scand J Work Environ Health 1978;4:295-303.

${ }^{3}$ Hanninen H, Hernberg S, Mantere P, Vesnato R, Jalkanen M. Psychological performance of subjects with low exposure to lead. J Occup Med 1978; 20:683-9.

${ }^{4}$ Repko JD, Corum CR, Jones PD, Garcia LS. The effects of inorganic lead on behavioral and neurologic function. Cincinnati: US Department of Health, Education, and Welfare, National Institute of Occupational Safety and Health, 1978. (Publication No 78-128.)

s Valciukas JA, Lilis R, Eisinger J, Blumberg WE, Fischbein A, Selikoff IF. Behavioral indicators of lead neurotoxicity: results of a clinical field survey. Int Arch Occup Environ Health 1978;41:217-36.

- Hogstedt C, Hane M, Agrell A, Bodin L. Neuropsychological test results and symptoms among workers with well-defined long-term exposure to lead. $\mathrm{Br}$ J Ind Med 1983;40:99-105.

' Akari S, Honma T, Yanagihara S, Ushio K. Recovery of slowed nerve conduction velocity in lead-expos əd workers. Int Arch Occup Environ Health 1980;46:151-7.

${ }^{8}$ Seppålåinen AM, Hernberg S. A follow-up study of nerve conduction velocities in lead exposed workers. Neurobehav Toxicol Teratol 1982;4:721-3.

' Spivey GH, Baloh RW, Brown CP, et al. Subclinical effects of chronic increased lead absorption: a prospective study, III. Neurological findings at follow-up examination.J Occup Med 1980;22:607-12.

1" Mantere P, Hanninen H, Hernberg S. Subclinical neurotoxic lead effects: two-year follow-up studies with psychological test methods. Neurobehav Toxicol Teratol 1982;4:725-7.

"Occupational Safety and Health Administration. Occupational exposure to lead-final standard. Federal Register 1978;43:52952-3014.

12 Baker EL, Feldman RG, White RF, Harley JP, Dinse GE, Berkey CS. Monitoring neurotoxins in industry-development of a neurobehavioral test battery.J Occup Med 1983;25:125-30.

${ }^{13}$ Lezak MD. Neuropsychological assessment. Oxford: Oxford University Press, 1980.

14 Wechsler D. A standardized memory scale for clinical use. J Psychol 1945; 19:87-95.

is Wechsler D. Wechsler adult intelligence scale manual. New York: Psychological Corporation, 1955.

${ }^{16}$ Rosvold H, Mirsky A, Sarason I, Bronsome E, Beck L. A continuous performance test of brain damage. J Consult Psychol 1956; 20: 343-50.

${ }^{17}$ McNair DM, Lorr M, Droppleman LF. EITS manual-profile of mood states. San Diego: Educational and Industrial Testing Service, 1971.

${ }^{18}$ Hanninen H, Lindstrom K. Behavioral test battery for toxicopsychological studies. Helsinki: Institute of Occupational Health, 1976.

${ }^{19}$ Searle B, Chan W, Davidow B. Determination of lead in blood and urine by anodic stripping voltammetry. Clin Chem 1973;19:76-80.

${ }^{20}$ Lamola AA, Yamane T. Zinc protoporphyrin in the erythrocytes of patients with lead intoxication and iron deficiency anemia. Science 1974;186:936.

"Holingshead AB, Redlick FC. Social class and mental illness. New York: Wiley, 1958.

${ }^{22}$ Selander $\mathrm{S}$. Treatment of lead poisoning. $\mathrm{Br} \mathrm{J}$ Ind Med 1967;24:272-82.

${ }^{23}$ Cullen MR, Robins JM, Eskenazi B. Adult lead intoxication: presentation of 31 new cases and a review of recent advances 
in the literature. Medicine 1983;62:221-47.

${ }^{24}$ Finkel AJ, Hamilton A, Hardy HL. Industrial toxicology. 4th ed. Boston: John Wright, PSG Inc, 1983.

${ }^{25}$ Needleman HL, Gunnow C, Leviton A, et al. Deficits in psychologic and classroom performance of children with elevated dentine lead levels. $N$ Engl J Med 1979;300:689-95.

${ }^{26}$ Struwe G, Mindus P, Jonsson B. Psychiatric ratings in occupational health research: a study of mental symptoms in lacquerers. Am J Ind Med 1980;1:23-30.

${ }^{27}$ Baker EL, Letz R, Fidler A. A computer-administered neurobehavioral evaluation system for occupational and environ- mental epidemiology. J Occup Med 1985;27:206-12.

28 Jensen AR. Bias in mental testing. New York: Free Press, 1980.

${ }^{29}$ Centers for Disease Control. Blood-lead levels in US population. Morbidity and Mortality Weekly Report 1982;31:132-4.

${ }^{30}$ Kehoe RA. Industrial lead poisoning. In: Irish DW, Fassett DW, eds. Patty: industrial hygiene and toxicology. Rev ed 2. New York: Interscience, 1963:941-85.

${ }^{31}$ Hernberg S. Biochemical and clinical effects and responses as indicated by blood concentration. In: Singhal RL, Thomas JA, eds. Lead toxicity. Baltimore: Urban and Schwarzenberg, 1980.

\section{Correspondence and editorials}

The British Journal of Industrial Medicine welcomes correspondence relating to any of the material appearing in the journal. Results from preliminary or small scale studies may also be published in the correspondence column if this seems appropriate. Letters should be not more than 500 words in length and contain a minimum of references. Tables and figures should be kept to an absolute minimum. Letters are accepted on the understanding that they may be subject to editorial revision and shortening.

The journal now also publishes editorials which are normally specially commissioned. The Editor welcomes suggestions regarding suitable topics; those wishing to submit an editorial, however, should do so only after discussion with the Editor. 